\title{
Comparison of the 6th and 7th Editions of the UICC TNM Staging System for Gastric Cancer: Results of a Chinese Single-Institution Study of 1,503 Patients
}

\author{
Wei Wang ${ }^{1,2}$, Xiao-wei Sun ${ }^{1,2}$, Chao-feng $\mathrm{Li}^{1,3}$, Lin $\mathrm{Lv}^{1}$, Yuan-fang $\mathrm{Li}^{1,2}$, Ying-bo Chen ${ }^{1,2}$, Da-zhi Xu, MD ${ }^{1,2}$, \\ Rajiv Kesari ${ }^{1,2}$, Chun-yu Huang ${ }^{1,2}$, Wei $\mathrm{Li}^{1,2}$, You-qing Zhan, $\mathrm{MD}^{1,2}$, and Zhi-wei Zhou, MD ${ }^{1,2}$ \\ ${ }^{1}$ State Key Laboratory of Oncology in South China, Guangzhou, China; ${ }^{2}$ Department of Gastric and Pancreatic Surgery, \\ Sun Yat-Sen University Cancer Center, Guangzhou, China; ${ }^{3}$ Department of Information Technology, Sun Yat-Sen \\ University Cancer Center, Guangzhou, China
}

\begin{abstract}
Aim. To evaluate the prognostic efficacy of the 7th edition tumor-node-metastasis (TNM) classification compared with the 6th edition in gastric cancer patients.

Methods. A total of 1,503 gastric cancer patients undergoing surgical resection were staged using the 6th and 7 th edition staging systems. Homogeneity, discriminatory ability, and monotonicity of gradients of the two systems were compared using linear trend $\chi^{2}$, likelihood ratio $\chi^{2}$ statistics, and Akaike information criterion (AIC) calculations.

Results. Significant differences in 5-year survival rates were observed for the T, $\mathrm{N}$, and $\mathrm{M}$ subgroups using the 7th edition system, except for stage $\mathrm{N} 2$ and $\mathrm{N} 3$ patients in the 6th edition system. There were no significant differences in survival between IB and IIA in the 7th edition system. Patients with stage IV disease due to T4/N3 in the 6th edition system who were downstaged to stage III in the 7th edition system had significantly better survival than those who remained at stage IV. The 7 th edition system had higher linear trend and likelihood ratio $\chi^{2}$ scores, and smaller AIC values compared with those for the 6th edition, which represented the optimum prognostic stratification.
\end{abstract}

Wei Wang and Xiao-wei Sun contributed equally to this work.

(C) The Author(s) 2010. This article is published with open access at Springerlink.com

First Received: 9 August 2010; Published Online: 24 November 2010

Z. Zhou, MD

e-mail: zhouzhw@sysucc.org.cn
Conclusions. Our study suggests that the 7 th edition system performs better than the 6th edition in several aspects.

Gastric cancer is the fourth most common malignant tumor in the world, with an estimated 1 million new cases every year. ${ }^{1}$ More new cases of gastric cancer are diagnosed in China each year than in any other country. ${ }^{2}$ Although current practice includes incorporating chemotherapy or radiation into the treatment protocol, surgical resection may remain the only chance for curing this disease. $^{3}$ Complete surgical resection with radical lymphadenectomy also provides information for accurate staging, which is very important in prognosis prediction and further therapy decisions.

The 6th edition American Joint Committee on Cancer (AJCC)/International Union against Cancer (UICC) tumornode-metastasis (TNM) staging system was published in $2002 .{ }^{4}$ In recent years, many modifications to the 6 th edition UICC TNM system have been proposed. This year, the UICC published the 7th edition TNM classification of malignant tumors for gastric cancer. ${ }^{5}$ In this edition, the $\mathrm{T}$ classification was changed to contain five subdivisions, namely T1, T2, T3, T4a, and T4b. Furthermore, subdivision of the $\mathrm{N}$ classification based on the number of metastatic lymph nodes was also changed. Finally, stage IV classification was redefined based on the presence of distant metastases, and the T4N+/TanyN3M0 classification, which was defined as stage IV in the 6th edition, was eliminated.

In this study, we aim to evaluate the efficacy and predictive ability of the 7th edition UICC TNM staging system and to compare the 6th and 7th editions of the UICC TNM staging system in a cohort of patients who underwent primary surgical resection for gastric cancer. 


\section{PATIENTS AND METHODS}

\section{Patients}

From January 1994 to December 2006, clinicopathological data from 1,503 cases of gastric cancer patients who underwent surgical resection at Sun Yat-Sen University Cancer Center were analyzed retrospectively. Eligibility criteria were: (1) gastric adenocarcinoma identified by histopathological examination, (2) application of gastrectomy plus lymphadenectomy (limited or extended), (3) complete follow-up data, (4) no history of familial malignancy or other synchronous malignancy [such as gastrointestinal stromal tumor (GIST), esophageal cancer, colorectal cancer, etc.], (5) no recurrent gastric cancer and remnant gastric cancer, and (6) no death in the perioperative period. The principles of tumor resection and D2 lymphadenectomy by experienced surgeons were similar in all radically resected patients.

\section{Follow-Up}

Postoperative follow-up included clinical and laboratory examinations every 3 months for the first 2 years at our outpatient department, every 6 months from the third to fifth years, and annually thereafter until at least 5 years after the operation or until the patient died, whichever came first. Overall patient survival, defined as time from operation to death or last follow-up, was used as a measure of prognosis.

\section{Statistics}

All patients were restaged using the 6th and 7th editions of the UICC TNM staging systems. Median overall survival (OS) was determined. Survival curves were plotted using the Kaplan-Meier method, and the log-rank test was used to determine significance. Factors that were deemed of potential importance on univariate analysis were included in multivariate analyses. Multivariate analysis of OS was performed by means of the Cox proportional-hazards model using the forward logistic regression (LR) stepwise procedure for variable selection. Also, since we thought that we needed to directly compare the 7th UICC TNM staging system with the 6th edition system, the likelihood ratio $\chi^{2}$ test related to the Cox regression model was used to measure homogeneity. The discriminatory ability and monotonicity of gradient assessments were measured with the linear trend $\chi^{2}$ test. To assess potential bias in comparing prognostic systems with different numbers of stages, the Akaike information criterion (AIC) within the Cox proportional-hazard regression model was used. The AIC statistic was defined by $\mathrm{AIC}=-2 \log$ maximum likelihood $+2 \times$ number of parameters in the model. A smaller AIC value indicated a better model for predicting outcome. $^{6,7}$ Hazard ratios (HR) and $95 \%$ confidence intervals $(95 \% \mathrm{CI})$ were generated. All calculations were performed using SPSS 18.0 software, and a $P$ value of less than 0.05 was considered significant.

\section{RESULTS}

Median follow-up for the entire cohort was 50 months (range 3-197 months). Mean age of the 1,503 patients was 56.21 (range 21-85) years; 999 were male, and 504 were female. The overall 5-year survival rate for all patients was $50.6 \%$, and 741 patients were alive when our follow-up was completed. The total number of lymph nodes harvested from all patients in this study was 22,244 (14.80 \pm 10.12$)$, of which $6,773(4.51 \pm 6.34)$ were positive. The incidence of nodal involvement was $68.1 \%$ overall $(1,024$ of 1,503 patients). One hundred sixty (10.6\%) patients were incidentally found to have distant metastases (abdominopelvic cavity, ovary, liver, or lung) during the operation and were classified as M1. No patients died during the initial hospital stay or first month after surgery.

\section{Univariate and Multivariate Survival Analysis}

In all 1,503 patients, 14 factors were found to have statistically significant associations with overall survival on univariate analysis. They were age, tumor location, tumor size, histological type, type of gastrectomy, radical resection, lymphatic/venous invasion, 6th and 7th UICC T stage, 6th and 7th UICC $\mathrm{N}$ stage, $\mathrm{M}$ stage, number of retrieved lymph nodes, and chemotherapy (Table 1). All of the aforementioned 14 variables were included in a multivariate Cox proportional-hazards model to adjust for effects of covariates. In our study, the $\mathrm{T}$ and $\mathrm{N}$ classifications in the 6th and 7th edition system were highly correlated. Therefore, two separate multivariate models, one with 7 th and the other with 6th edition system, were run to avoid problems with presence of multicollinearity. In that model, we demonstrated that age, tumor size, histological grade, lymphatic/venous invasion, $\mathrm{T}, \mathrm{N}$, and $\mathrm{M}$ stage, and retrieved lymph nodes remained independent prognostic factors (Table 2). Tumor location, type of gastrectomy, radical resection, and chemotherapy-all of which were significant prognostic factors on univariate analysis-did not show significant influence on multivariate analysis. Concerning radical resection, we believe its prognostic value was overlapped by the $\mathrm{M}$ stage, and thus it did not show significant influence on multivariate analysis. Concerning chemotherapy, although patients in the adjuvant treatment group showed better 5-year survival rates on 
TABLE 1 Univariate survival analysis of clinicopathologic variables in 1,503 cases of gastric cancer patients

\begin{tabular}{llll}
\hline Variable & $N(\%)$ & $\begin{array}{l}\text { 5-Year } \\
\text { survival } \\
\text { rate }(\%)\end{array}$ & $\begin{array}{l}\text { Log } \\
\text { rank } \chi^{2} \\
\text { value }\end{array}$ \\
\hline
\end{tabular}

\begin{tabular}{|c|c|c|}
\hline Gender & & $0.000 \quad 0.984$ \\
\hline Female & 999 (66.5) 50.8 & \\
\hline Male & $504(33.5) \quad 50.3$ & \\
\hline
\end{tabular}

Age (years)

$\leq 40$
$41-60$
$>61$

Tumor location

Proximal

Middle

Distal

Two-thirds or more

Tumor size $(\mathrm{cm})$

$$
\leq 5.0
$$$$
>5.0
$$

Histological grade

Well/moderately

differentiated

adenocarcinoma

Poorly differentiated adenocarcinoma

Undifferentiated

adenocarcinoma/

signet-ring cell

carcinoma/mucinous adenocarcinoma

Type of gastrectomy

Proximal subtotal

Distal subtotal

Total

Radical resection

Yes

No

Lymphatic/venous invasion

No

Yes

Depth of invasion (6th edition)

$\mathrm{T} 1$

$\mathrm{T} 2$

T3

$\mathrm{T} 4$

Depth of invasion (7th edition)

$\begin{array}{lll}\mathrm{T} 1 & 119(7.9) & 96.6 \\ \mathrm{~T} 2 & 176(11.7) & 74.5 \\ \mathrm{~T} 3 & 264(17.6) & 64.0\end{array}$

$74.616 \quad 0.000$

603 (40.1) 45.2

$721(48.0) \quad 59.9$

179 (11.9) 31.5

$408.405 \quad 0.000$

$1,285(85.5) \quad 57.9$

218 (14.5) 7.6

$169.779 \quad 0.000$

1,361 (90.6) 54.1

$142(9.4) \quad 17.6$

$242.021 \quad 0.000$

119 (7.9) 96.6

440 (29.3) 68.3

793 (52.8) 39.3

$151(10.0) \quad 23.4$

$246.457 \quad 0.000$
TABLE 1 continued

\begin{tabular}{llll}
\hline Variable & $N(\%)$ & $\begin{array}{l}\text { 5-Year } \\
\text { survival } \\
\text { rate }(\%)\end{array}$ & $\begin{array}{l}\text { Log } \\
\text { rank } \chi^{2} \\
\text { value }\end{array}$ \\
& & $P$ value \\
&
\end{tabular}

\begin{tabular}{|c|c|c|c|c|}
\hline $\mathrm{T} 4 \mathrm{a}$ & $793(52.8)$ & 39.3 & & \\
\hline $\mathrm{T} 4 \mathrm{~b}$ & $151(10.0)$ & 23.4 & & \\
\hline $\begin{array}{l}\text { Nodal status (6th } \\
\text { edition) }\end{array}$ & & & 234.697 & 0.000 \\
\hline No & 479 (31.9) & 75.3 & & \\
\hline N1 & $665(44.2)$ & 46.1 & & \\
\hline $\mathrm{N} 2$ & $269(17.9)$ & 26.5 & & \\
\hline N3 & $90(6.0)$ & 24.8 & & \\
\hline $\begin{array}{l}\text { Nodal status ( } 7 \text { th } \\
\text { edition) }\end{array}$ & & & 248.594 & 0.000 \\
\hline No & 479 (31.9) & 75.3 & & \\
\hline N1 & $298(19.8)$ & 53.6 & & \\
\hline $\mathrm{N} 2$ & $367(24.4)$ & 39.9 & & \\
\hline N3a & $269(17.9)$ & 26.5 & & \\
\hline $\mathrm{N} 3 \mathrm{~b}$ & $90(6.0)$ & 24.8 & & \\
\hline Metastasis & & & 312.744 & 0.000 \\
\hline M0 & $1,344(89.4)$ & 55.9 & & \\
\hline M1 & $159(10.6)$ & 5.6 & & \\
\hline Retrieved lymph nodes & & & 70.972 & 0.000 \\
\hline$<15$ & $837(55.7)$ & 40.9 & & \\
\hline$\geq 15$ & $666(44.3)$ & 63.1 & & \\
\hline Chemotherapy & & & 6.173 & 0.013 \\
\hline Yes & $620(41.3)$ & 53.6 & & \\
\hline No & $883(58.7)$ & 48.5 & & \\
\hline
\end{tabular}

univariate analysis $(P=0.013)$, these values did not reach significance on multivariate analysis. This finding probably reflects selection bias, because adjuvant therapy was offered to more advanced-stage patients.

In our database, the survival curves in each $\mathrm{T}$ subgroup in the 7th edition staging system had excellent discriminatory abilities $(P=0.000,0.003,0.000$, and 0.000 , respectively), which was also observed for subgroups in the 6th edition ( $P=0.000,0.000$, and 0.000 , respectively). In the 6th edition staging system, $\mathrm{N}$ stage was categorized as N0 (no regional lymph node metastasis), N1 (metastasis in 1-6 nodes), N2 (metastasis in 7-15 nodes), and N3 (metastasis in 15 or more nodes). By contrast, according to the 7th edition TNM classification system, $\mathrm{N}$ stage was reclassified as N0 (no regional lymph node metastasis), N1 (metastasis in 1-2 nodes), N2 (metastasis in 3-6 nodes), and N3 (metastasis in 7 or more nodes). The Kaplan-Meier plot for the 6th edition showed discriminative survival curves for N0 versus $\mathrm{N} 1$ and $\mathrm{N} 1$ versus $\mathrm{N} 2(P=0.000$ and 0.000 , respectively) but not for N2 versus N3 $(P=0.780)$. In the 7th edition, the Kaplan-Meier plot showed discriminatory ability among the subgroups of N0 versus N1, 
TABLE 2 Multivariate survival analysis results

\begin{tabular}{|c|c|c|c|c|c|c|c|}
\hline \multicolumn{8}{|l|}{ Variables in the equation } \\
\hline Variables & $B$ & SE & Wald & $P$ & HR & $95 \% \mathrm{CI}$ & \\
\hline \multicolumn{8}{|c|}{ 7th edition of the AJCC/UICC TNM staging system } \\
\hline Age & 0.148 & 0.058 & 6.378 & 0.012 & 1.159 & 1.034 & 1.300 \\
\hline Tumor size & 0.433 & 0.076 & 32.531 & 0.000 & 1.543 & 1.329 & 1.790 \\
\hline Histological grade & 0.150 & 0.051 & 8.651 & 0.003 & 1.162 & 1.051 & 1.283 \\
\hline Lymphatic/venous invasion & 0.909 & 0.105 & 75.095 & 0.000 & 2.481 & 2.020 & 3.047 \\
\hline AJCC/UICC 7th T & & & 59.270 & 0.000 & & & \\
\hline $\mathrm{T} 1$ (reference) & & & & & 1.000 & & \\
\hline $\mathrm{T} 2$ & 1.731 & 0.524 & 10.893 & 0.001 & 5.644 & 2.020 & 15.774 \\
\hline $\mathrm{T} 3$ & 1.978 & 0.516 & 14.729 & 0.000 & 7.231 & 2.633 & 19.862 \\
\hline $\mathrm{T} 4 \mathrm{a}$ & 2.424 & 0.509 & 22.708 & 0.000 & 11.289 & 4.166 & 30.593 \\
\hline $\mathrm{T} 4 \mathrm{~b}$ & 2.661 & 0.518 & 26.419 & 0.000 & 14.313 & 5.188 & 39.486 \\
\hline AJCC/UICC 7th N & & & 115.623 & 0.000 & & & \\
\hline N0 (reference) & & & & & 1.000 & & \\
\hline N1 & 0.491 & 0.124 & 15.659 & 0.000 & 1.634 & 1.281 & 2.085 \\
\hline $\mathrm{N} 2$ & 0.726 & 0.116 & 39.449 & 0.000 & 2.068 & 1.648 & 2.594 \\
\hline $\mathrm{N} 3$ & 10.271 & 0.122 & 108.170 & 0.000 & 3.564 & 2.805 & 4.528 \\
\hline AJCC/UICC 7th M & 0.798 & 0.100 & 63.484 & 0.000 & 2.220 & 1.825 & 2.701 \\
\hline Retrieved lymph nodes & -0.826 & 0.086 & 91.919 & 0.000 & 0.438 & 0.370 & 0.518 \\
\hline \multicolumn{8}{|c|}{ 6th edition of the AJCC/UICC TNM staging system } \\
\hline Age & 0.150 & 0.058 & 6.617 & 0.010 & 1.162 & 1.036 & 1.302 \\
\hline Tumor size & 0.436 & 0.076 & 32.843 & 0.000 & 1.546 & 1.332 & 1.794 \\
\hline Histological grade & 0.157 & 0.051 & 9.555 & 0.002 & 1.170 & 1.059 & 1.293 \\
\hline Lymphatic/venous invasion & 0.907 & 0.105 & 74.763 & 0.000 & 2.478 & 2.017 & 3.044 \\
\hline AJCC/UICC 6th T & & & 59.969 & 0.000 & & & \\
\hline $\mathrm{T} 1$ (reference) & & & & & 1.000 & & \\
\hline $\mathrm{T} 2$ & 1.849 & .512 & 13.048 & 0.000 & 6.354 & 2.330 & 17.328 \\
\hline $\mathrm{T} 3$ & 2.400 & .509 & 22.259 & 0.000 & 11.025 & 4.068 & 29.882 \\
\hline $\mathrm{T} 4$ & 2.626 & .518 & 25.729 & 0.000 & 13.818 & 5.009 & 38.114 \\
\hline AJCC/UICC 6th N & & & 117.338 & 0.000 & & & \\
\hline N0 (reference) & & & & & 1.000 & & \\
\hline N1 & 0.634 & 0.107 & 35.304 & 0.000 & 1.885 & 1.529 & 2.323 \\
\hline $\mathrm{N} 2$ & 1.221 & 0.126 & 94.533 & 0.000 & 3.391 & 2.651 & 4.337 \\
\hline $\mathrm{N} 3$ & 1.565 & 0.178 & 76.996 & 0.000 & 4.783 & 3.372 & 6.784 \\
\hline AJCC/UICC 6th M & 0.813 & 0.100 & 65.517 & 0.000 & 2.255 & 1.852 & 2.746 \\
\hline Retrieved lymph nodes & -0.885 & 0.092 & 93.426 & 0.000 & 0.413 & 0.345 & 0.494 \\
\hline
\end{tabular}

$H R$ hazard ratio, $C I$ confidence interval, $T$ tumor, $N$ node, $M$ metastasis

$\mathrm{N} 1$ versus $\mathrm{N} 2$, and $\mathrm{N} 2$ versus $\mathrm{N} 3(P=0.000,0.000$, and 0.000 , respectively) (Fig. 1).

Figure 2 shows the patient distribution and stage-specific survival rates. In the 6th edition staging system, the Kaplan-Meier plot showed no overlapping survival curves among the six subgroups. In the 7th edition, among all eight substages, there were similar survival curves between stages IB and IIA $(P=0.261)$, while the Kaplan-Meier plot showed good discriminatory ability among other substages. However, when classified as four major stages, the Kaplan-Meier plot showed good discriminatory ability among stages I through IV in both systems.

The performance of the 6th and 7th edition staging systems as assessed by the linear trend $\chi^{2}$, likelihood ratio $\chi^{2}$, and the AIC tests is presented in Table 3. Compared with the 6th edition system, the 7th edition system had better homogeneity (higher likelihood ratio $\chi^{2}$ score), discriminatory ability, and monotonicity of gradients (higher 
FIG. 1 Comparison of survival curves according to $\mathrm{T}$ between the 6th (a) and 7 th edition (b), and $\mathrm{N}$ classifications between the 6th (c) and 7th edition (d)
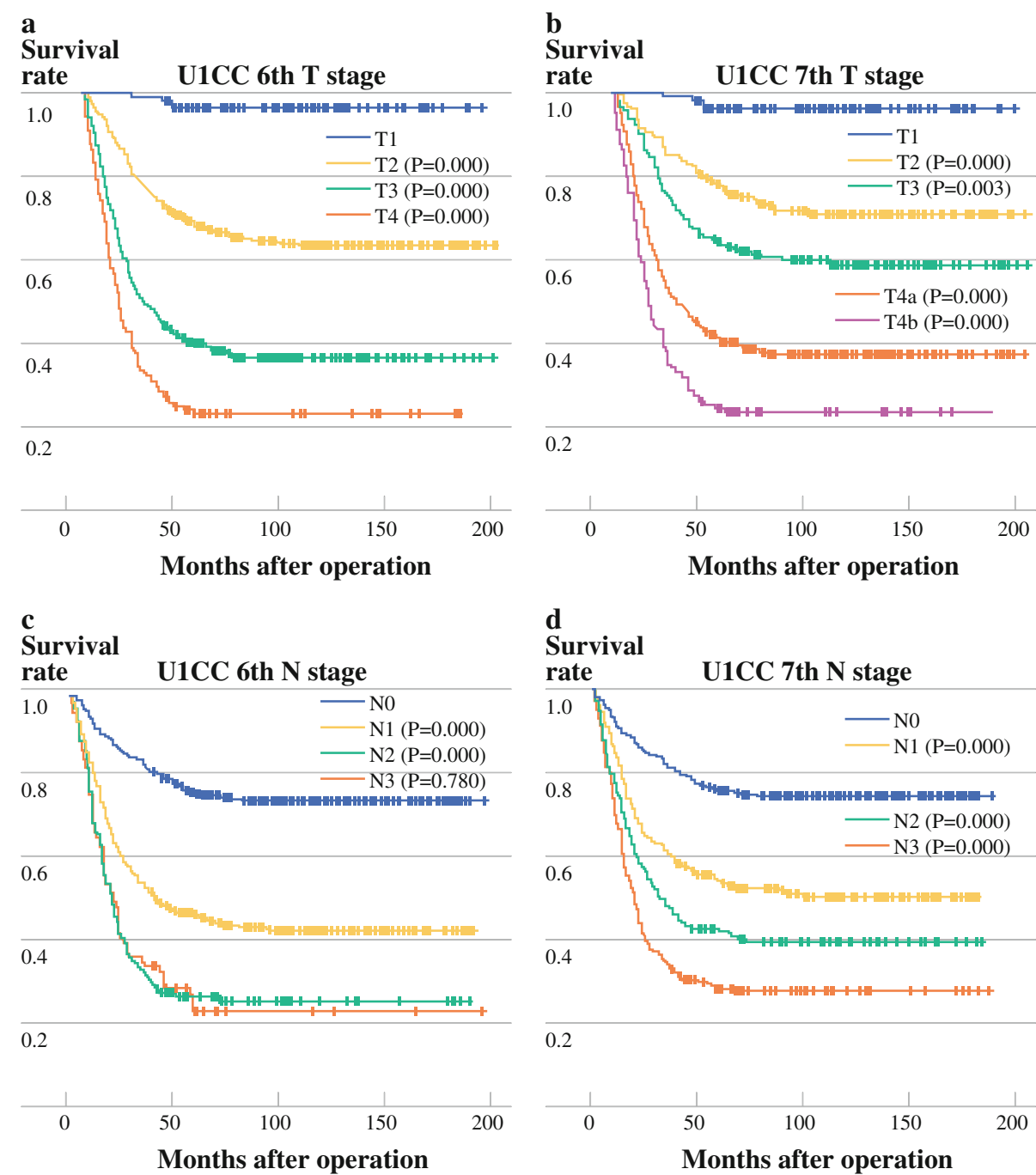

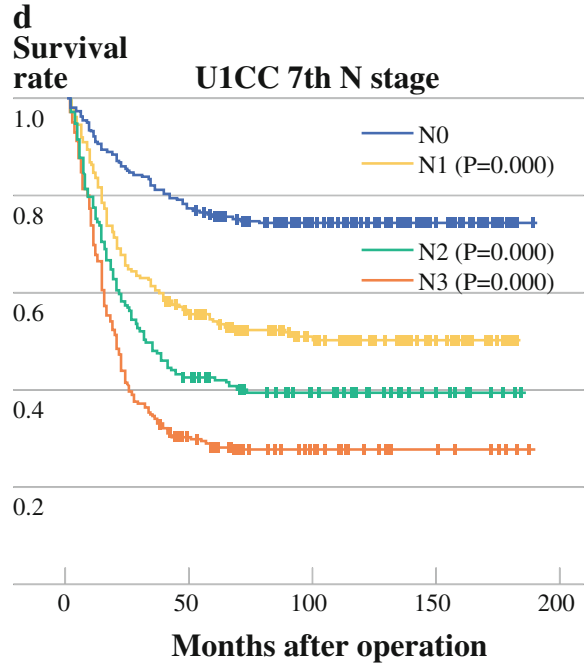

linear trend $\chi^{2}$ score). Furthermore, the 7 th edition system had a smaller AIC value, representing optimum prognostic stratification.

To obtain the best classification of substages for prognosis evaluation of gastric cancer in our statistical analysis, we used stratified analysis to introduce the factor of tumor size into substages of 92 cases of IB and 150 cases of IIA. We found that, in both subgroups of tumor size $\leq 5$ and $>5 \mathrm{~cm}$, substage IB patients had significantly longer survival than substage IIA patients. In the subgroup of tumor size $\leq 5 \mathrm{~cm}$, the 5-year survival rate of stage IB and IIA patients was 95.5 and $84.2 \%$, respectively $(P=0.042)$, and in the subgroup of tumor size $>5 \mathrm{~cm}$, the 5-year survival rate of stage IB and IIA patients was 73.9 and $56.8 \%$, respectively $(P=0.043)$.

In our study, among 331 cases of stage IV disease in the 6th edition system, 160 cases $(48.3 \%)$ remained in stage IV while 130 cases $(39.3 \%)$ were downstaged to IIIC, 40 cases $(12.1 \%)$ to IIIB, and 1 case $(0.3 \%)$ to IIIA in the 7 th edition system. Therefore, we compared the prognosis of patients who remained in stage IV and those who were downstaged to stage III. We found that patients downstaged to stage III had better prognosis than those who remained in stage IV, with 5-year survival rates of $28.6 \%$ and $5.6 \%$, respectively $(P=0.000)$. Even when divided into three subgroups (group 1, stage IIIB: T3N3bM0, T4bN1M0; group 2, stage IIIC: T4bN2-3bM0, T4a-4bN3bM0; and group 3, stage IV: $\mathrm{T}$ [any]N[any]M1) according to the 7 th edition system, the patients had distinguishable prognoses. Subgroup 1 had a significantly better overall survival rate than subgroups 2 and 3 ( $P=0.039$ and 0.000 , respectively) (Fig. 3 ).

\section{DISCUSSION}

The TNM classification system attempts to account for most basic parameters of cancer, and it has utility for determining extent of disease, providing guidance for treatment planning, and predicting outcome. The most substantial major changes for the 7th edition UICC TNM staging system are described below. 
FIG. 2 Comparison of survival curves according to 6th and 7th editions. a, b classified as four major stages in the 6th and 7th editions, c classified as six substages in the 6th edition, and d classified as eight substages in the 7 th edition $(P=0.000$, respectively) a UICC 6th ed. system

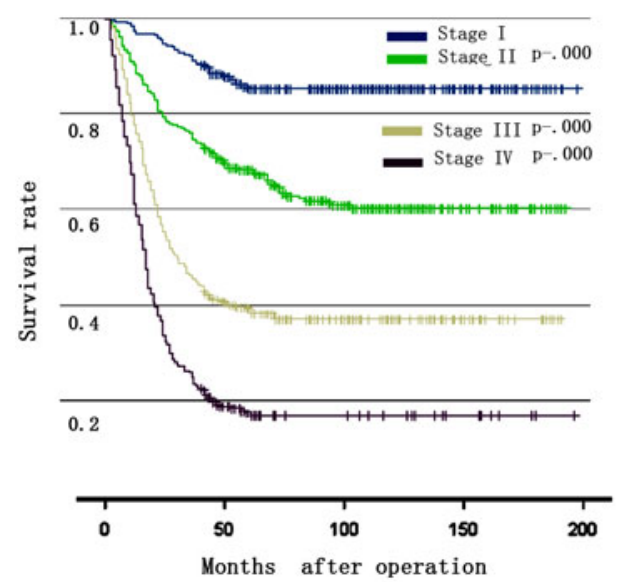

C UICC 6th ed. system

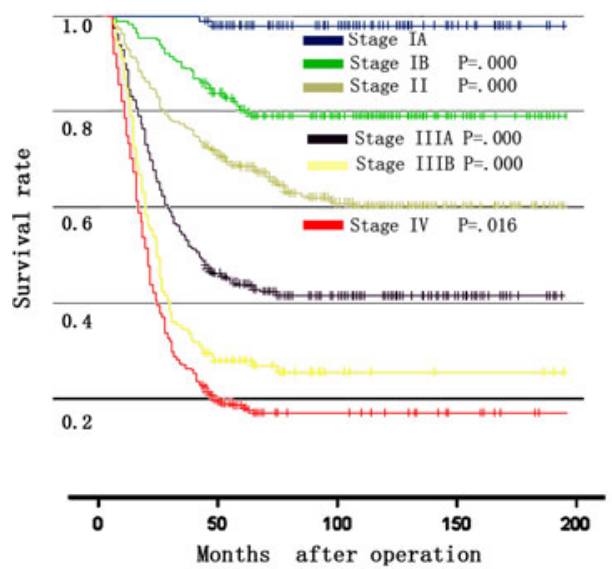

b VICC 7 th ed. system

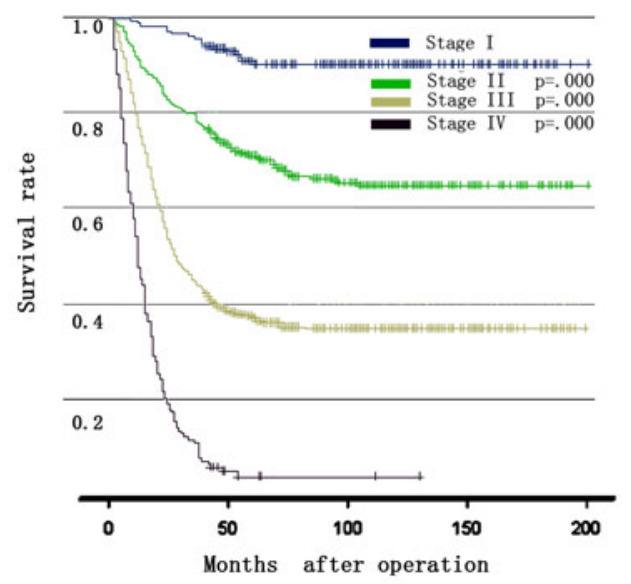

d UICC 7th ed. system

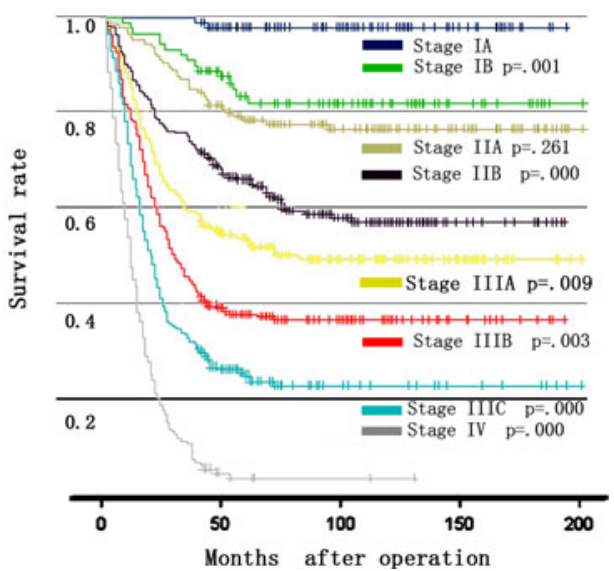

TABLE 3 Comparison of the performance of the 6th and 7th editions of the AJCC/UICC TNM staging system

\begin{tabular}{llllll}
\hline TNM staging system & Figure & Subgroups & Linear trend $\chi^{2}$ & Likelihood ratio $\chi^{2}$ & AIC \\
\hline 6th edition & 2A & I, II, III, IV & 341.715 & 371.501 & 10240.957 \\
\multirow{3}{*}{ 7th edition } & 2C & IA, IB, II, IIIA, IIIB, IV & 356.194 & 406.347 & 10231.377 \\
& 2B & I, II, III, IV & 348.459 & 397.968 & 10201.315 \\
& 2D & IA, IB, IIA, IIB, IIIA, IIIB, IIIC, IV & 386.318 & 451.862 & 10162.560 \\
\hline
\end{tabular}

AIC Akaike information criterion

Firstly, concerning $\mathrm{T}$ classification, the $\mathrm{T} 2$ stage in the 6th edition system was subdivided into $\mathrm{T} 2$ and $\mathrm{T} 3$ in the 7 th edition system, and directly resulted in two additional substages in the 7 th edition system in addition to the six substages in the 6th edition system. Although substages IB and IIA had no significant difference in survival rates, we suppose that this finding was caused by differences of composition and the relatively small number of cases in these two substages. In our database, subgroups T2 and T3 had significantly different survival curves. Therefore, we believe the indistinguishable survival curves between substages IB and IIA were caused by the $\mathrm{N}$ status in these two substages. Substage IB was composed of 9 cases of T1N1M0 and 83 cases of T2N0M0, and substage IIA was composed of 8 cases of T1N2M0, 42 cases of T2N1M0, and 100 cases of T3NOM0. However, when we incorporated tumor size to subclassify stage IB and IIA in the 7th edition system, the role of tumor size in gastric cancer patient survival became important. On univariate and Cox regression multivariate analyses, we determined tumor size 
Stage IV patients in 6 th edition systenm

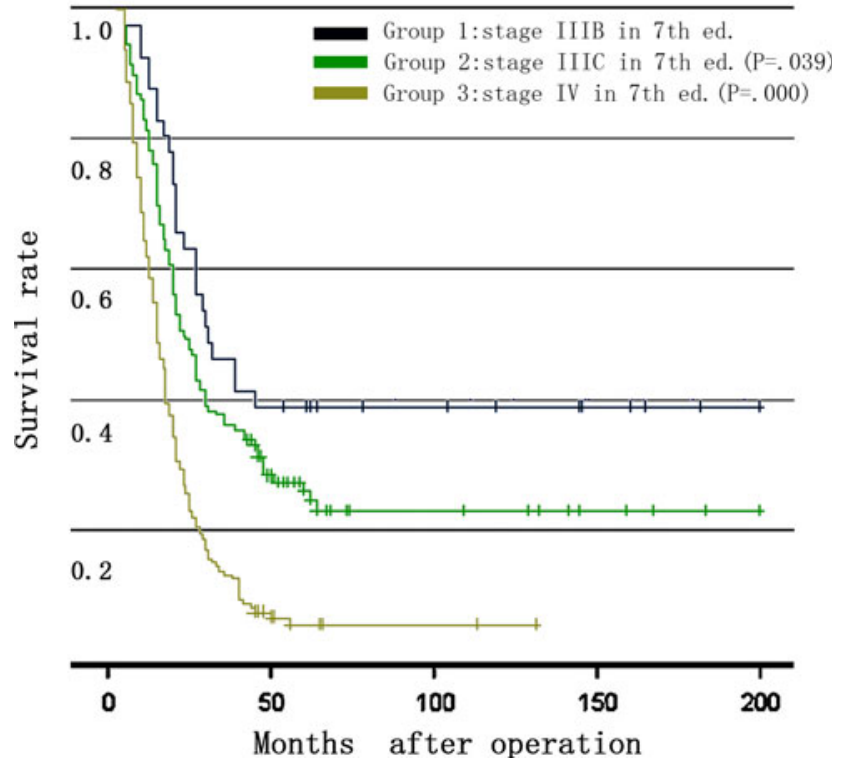

FIG. 3 Comparison of survival curves between patients downstaged to stage IIIB and IIIC and those remaining in stage IV in the 7th edition system $(P=0.039$ and 0.000 , respectively)

to be an independent prognostic factor. On stratified analysis, we found that, in both subgroups of tumor size $\leq 5 \mathrm{~cm}$ and $>5 \mathrm{~cm}$, patients in substage IB had better prognoses than did those in substage IIA. Park and colleagues found subclassification of pT2 gastric cancers into pT2a or pT2b to be necessary to demonstrate their different prognoses according to the 6th edition system based on 1,118 cases of gastric cancer. ${ }^{8}$ Liu et al. found tumor size to be an independent prognostic factor for patients with T3 gastric cancer in the 6th edition system, and the 5-year survival rates were 29.5 and $42.7 \%$ in the large-size (LSG, tumor $>6 \mathrm{~cm}$ ) and small-size groups ( $\mathrm{SSG}$, tumor $\leq 6 \mathrm{~cm}$ ), respectively $(P=0.045){ }^{9}$

Secondly, the subdivision of $\mathrm{N}$ classification based on the number of metastatic lymph nodes was changed. The $\mathrm{N} 1$ substage in the old system was divided into N1 and N2 in the new system, and $\mathrm{N} 2$ and $\mathrm{N} 3$ substages were merged into N3. Nodal status is a singularly important prognostic factor in gastric cancer. Actually, many studies had demonstrated $\mathrm{N}$ stage in the 6th edition system to be not suitable for prognostic prediction in clinical analysis, because of the inappropriate cutoffs of that stage. Deng et al. determined the most appropriate cutoffs of metastatic lymph nodes to be $0,1-4,5-8$, and $\geq 9$ in 308 gastric cancer cases with curative resection classified by the 6th edition system. ${ }^{10}$ In a group of multicenter retrospective studies in Italy based on 652 resected early gastric cancer cases classified by the 6th edition system, Roviello et al. found the 10-year survival rate in early gastric cancer patients to be $92 \%$ for patients with negative nodes, $82 \%$ for patients with $1-3$ positive nodes, $73 \%$ for $4-6$ positive nodes, and $27 \%$ for $>6$ positive nodes. ${ }^{11}$ Similarly, using multivariate analysis including the number of positive nodes with cutoffs of $0,1-4,5-8$, and $\geq 9$, Wu et al. ${ }^{12}$ reported that the category of positive nodes was the most important prognostic indicator for 510 gastric cancer cases. In accordance with Deng et al., N2 and N3 patients in our study using the 6th edition system (equivalent to $\mathrm{N} 3 \mathrm{a}$ and N3b in the 7th edition) had similar survival. ${ }^{13}$ The studies mentioned above show that the 6th edition UICC $\mathrm{N}$ stage less accurately reflected patient prognosis. Therefore, our results indicated that identifying lymph node metastases and classifying patients as N3a and N3b are unnecessary.

Thirdly, partial cases of stage IV disease due to T4 or $\mathrm{N} 3$ in the 6th edition system were downstaged to IIIC, IIIB, and IIIA in the 7th edition system. An et al. reported each subgroup of stage IV gastric cancer in the 6th edition system to have different clinical outcomes, and thus subclassification of stage IV gastric cancer into IVA (T1-3N3M0), IVB (T4N1-3M0), and IVM (T[any]N[any]M1) might be useful for more accurate prediction of prognosis. ${ }^{14}$ Ma et al. ${ }^{15}$ also predicted that subclassification of stage IV gastric cancer into IVA (T1-2N3M0), IVB (T3N3M0 and T4N1-2M0), and IVC (T4N3M0, TanyNanyM1) may be helpful to predict the outcome for patients with stage IV gastric cancer as classified by the 6th edition system. Additionally, Ahn et al. determined that survival for $\mathrm{pN} 3$ gastric cancer patients after curative gastrectomy was significantly longer in the $\mathrm{pN} 3 / \mathrm{M} 0$ group as compared with that of the $\mathrm{pN} 3 / \mathrm{M} 1$ group, and advanced $\mathrm{T}$ stage was a predictor of poor prognosis for $\mathrm{pN} 3$ patients based on 467 cases of gastric cancer patients classified by the 6th edition system. ${ }^{16}$ Park et al. ${ }^{17}$ found survival of patients with T4N3M0 and M1 stage disease to be significantly shorter than that of patients with T1-3N3M0 and T4N1-2M0 stage disease $(P=0.000)$ in a 422-patient study. They suggested that subclassification of stage IV gastric cancer into IVa (T1-3N3M0, T4N1-2M0) and IVb (T4N3M0, T[any] N[any]M1) may help predict the outcome of patients with stage IV gastric cancer as classified by the 6th edition system. In our study, we also demonstrated that patients with stage IV in the 6th edition system could be divided into two subgroups. Patients downstaged to stage III in the 7th edition system had significantly better prognosis than did those who remained in stage IV. Even when we divided these patients into three substages (stage IIIB, IIIC, and IV) according to the 7th edition system, the patients still had distinguishable prognoses. In our database, only one case was categorized as having stage IIIA disease in the 7th edition system, so we excluded this patient from the survival analysis because the number of patients enrolled was 
too small. This phenomenon may be explained by the fact that the three subgroups have different biologic behaviors of relapse or metastasis models, which still merits further research.

According to the theory mentioned by Ueno and colleagues, the criteria for evaluating the performance of the staging systems were as follows: (1) homogeneity within subgroups (small differences in survival among patients within same stage), (2) discriminatory ability between different groups (greater differences in survival among patients in different stages), and (3) monotonicity of gradients shown in the association between stages and survival rates (patients with earlier stages have longer survival than those in later stages) ${ }^{18}$ In the 6th edition staging system, the survival rate of the six substages had significant differences, while in the 7th edition system, the discriminatory ability between the eight substages appeared more powerful. As shown above, the new system had better homogeneity, discriminatory ability, and monotonicity of gradients. Additionally, the new system had a smaller AIC value, representing optimum prognostic stratification.

\section{CONCLUSIONS}

Although our sample population was from a singleinstitution experience and is relatively small compared with the worldwide gastric cancer collaboration database, the surgical procedures, pathologic examinations, and patient follow-up were highly uniform throughout the entire study period. Strengths of the 7th edition UICC TNM staging system include redefinition of T classification, redescription for $\mathrm{N}$ classification based on the number of positive lymph nodes, and reclassification of stage IV disease. Based on analysis of 1,503 gastric cancer patients who underwent primary surgical resection, we provided an external validation of the new UICC TNM staging system. Furthermore, we found that several clinicopathological variables, especially tumor size, were significant prognostic factors in our database worthy of further research. Overall, the 7th edition UICC TNM staging system is superior to the 6th edition system in terms of homogeneity, discriminatory, and monotonicity of gradients.

ACKNOWLEDGMENT Supported by Science and Technology Projects by Guangdong Province (2008B030301103).

DISCLOSURE All authors stated that they have no personal or financial conflict of interest.

OPEN ACCESS This article is distributed under the terms of the Creative Commons Attribution Noncommercial License which permits any noncommercial use, distribution, and reproduction in any medium, provided the original author(s) and source are credited.

\section{REFERENCES}

1. Garcia M, Jemal A, Ward EM, et al. (2007) Global cancer facts and figures 2007. American Cancer Society, Atlanta.

2. Jemal A, Siegel R, Ward E, Hao Y, Xu J, Thun MJ. Cancer statistics, 2009. CA Cancer J Clin. 2009;59:225-49.

3. Ajani JA, Barthel JS, Bekaii-Saab T. NCCN Clinical practice guidelines in oncology, gastric cancer, v.2. 2010. www.nccn.org.

4. Sobin LH, Wittekind C. International Union Against Cancer (UICC) TNM classification of malignant tumours, 6th edition. New York: Wiley; 2002.

5. Sobin LH, Gospodarowicz MK, Wittekind C. International Union Against Cancer (UICC) TNM classification of malignant tumours, 7th edition. New York: Wiley-Liss; 2010.

6. Kee KM, Wang JH, Lee CM, et al. Validation of clinical AJCC/ UICC TNM staging system for hepatocellular carcinoma: analysis of 5,613 cases from a medical center in southern Taiwan. Int J Cancer. 2007;120:2650-5.

7. Cho YK, Chung JW, Kim JK, et al. Comparison of 7 staging systems for patients with hepatocellular carcinoma undergoing transarterial chemoembolization. Cancer. 2008;112:352-61.

8. Park do J, Kong SH, Lee HJ, et al. Subclassification of pT2 gastric adenocarcinoma according to depth of invasion (pT2a vs pT2b) and lymph node status (pN). Surgery. 2007;141:757-63.

9. Liu X, Xu Y, Long Z, Zhu H, Wang Y. Prognostic significance of tumor size in T3 gastric cancer. Ann Surg Oncol. 2009;16: $1875-82$.

10. Deng JY, Liang H, Sun D, Zhan HJ, Wang XN. The most appropriate category of metastatic lymph nodes to evaluate overall survival of gastric cancer following curative resection. J Surg Oncol. 2008;98:343-8.

11. Roviello F, Rossi S, Marrelli D, et al. Number of lymph node metastases and its prognostic significance in early gastric cancer: a multicenter Italian study. J Surg Oncol. 2006;94:275-80 (discussion 4)

12. Wu CW, Hsieh MC, Lo SS, Tsay SH, Lui WY, P'Eng F K. Relation of number of positive lymph nodes to the prognosis of patients with primary gastric adenocarcinoma. Gut.1996;38: $525-7$.

13. Deng J, Liang H, Sun D, Wang D, Pan Y. Suitability of 7th UICC $\mathrm{N}$ stage for predicting the overall survival of gastric cancer patients after curative resection in China. Ann Surg Oncol. 2010;17:1259-66.

14. An JY, Ha TK, Noh JH, Sohn TS, Kim S. Proposal to subclassify stage IV gastric cancer into IVA, IVB, and IVM. Arch Surg. 2009; 144:38-45 (discussion 45).

15. Ma Y, Xue Y, Li Y, Lan X, Zhang Y, Zhang M. Subclassification of stage IV gastric cancer (IVa, IVb, and IVc) and prognostic significance of substages. J Gastrointest Surg. 2010;14:484-92.

16. Ahn JR, Jung M, Kim C, et al. Prognosis of $\mathrm{pN} 3$ stage gastric cancer. Cancer Res Treat. 2009;41:73-9.

17. Park JM, Park SS, Mok YJ, Kim CS. pN3M0 gastric cancer: the category that allows the sub-classification of stage-IV gastric cancer (IVa and IVb). Ann Surg Oncol. 2007;14:2535-42.

18. Ueno S, Tanabe G, Sako K, et al. Discrimination value of the new western prognostic system (CLIP score) for hepatocellular carcinoma in 662 Japanese patients. Cancer of the Liver Italian Program. Hepatology. 2001;34:529-34. 